\title{
Improving zinc phytoremediation characteristics in Salix pedicellata with a new acclimation approach
}

Ryad Amdoun $^{\mathrm{a}}$, Nassim Bendifallah ${ }^{\mathrm{a}}$, Fatiha Sahli ${ }^{\mathrm{a}}$, Khaled Moustafa ${ }^{\mathrm{b}}$, Kathleen Hefferon ${ }^{\mathrm{c}}$, Abdallah Makhzoum ${ }^{\mathrm{d}}$, and Lakhdar Khelifi ${ }^{\mathrm{e}}$

${ }^{a}$ Institut National de la Recherche Forestière (INRF). BP 37 Chéraga Alger. Algeria.

${ }^{\mathrm{b}}$ Arabic Science Archive--ArabiXiv (https://arabixiv.org).

${ }^{c}$ Cornell University College of Agriculture and Life Sciences, Food Science and Technology, Ithaca, New York, USA.

${ }^{\mathrm{d}}$ Department of Biological Sciences and Biotechnology, Botswana International University of Science and Technology, Palapye, Botswana.

dLaboratoire des Ressources Génétiques et Biotechnologie, Ecole Nationale Supérieure Agronomique (ES1603), 16200 El-Harrach, Alger, Algérie.

\begin{abstract}
Salix sp. (willows) is a phytoremediator plant species that can accumulate and detoxify soils contaminated with pollutants and toxic heavy metals such as zinc. However, high concentrations of zinc inhibit plant growth and reduce biomass accumulation. In an attempt to overcome this inconvenience and to enhance plant adaptive abilities to zinc toxicity, we tested a new phytoremediation procedure in two clones of Salix pedicellata, named SPK-12 and SP-K20. The approach comprises two successive phases. The first is an "induction phase" consisting of gradual exposure of plants to low concentrations of zinc sulfate $\left(\mathrm{ZnSO}_{4}\right)$ at short and regular intervals. And, the second is a "maintenance phase" to uphold the acquired tolerance to zinc as long as possible. One of the two clones, SP-K20, tolerated up to $20 \mathrm{mg} / \mathrm{L} \mathrm{ZnSO}_{4}$ over 33 days without noticeable symptoms of chlorosis or growth inhibition. The SP-K20 clone was also able to accumulate high concentrations of zinc in its tissues, suggesting that phytoremediation abilities of Salix have been improved throughout the applied approach.
\end{abstract}

Keywords: heavy metal tolerance, phytoremediation, phytotoxicity, Salix clones, Salix pedicellata, willow, zinc cytotoxicity, zinc tolerance.

\section{Introduction}


The toxicity of heavy metals in soil is an important issue for agriculture worldwide. Mining industry and industrial wastes along with fossil fuels and agricultural chemicals are major sources of toxic pollutants in the soil, air and water (Nriagu and Pacyna 1988). As pollutants can be consumed through food products, heavy metals also raise important health concerns for the public (Jabeen et al. 2009) (Yadav et al. 2018). At low concentrations, however, heavy metals such as zinc play important roles in plant metabolism and physiological functions, but they turn into phytotoxic minerals when their concentrations exceed some critical threshold (Broadley et al. 2007). Zinc phytotoxicity is mostly observed in soils contaminated with mining industry wastes, smelting activities and agricultural soils treated with sewage sludge particularly in acidic soils (Chaney 1993). The main physiological indicators of zinc toxicity in plants include; decrease of biomass accumulation, low yield, slow growth, and chlorosis (Ebbs and Kochian 1997) (Nagajyoti et al. 2010). To avoid such damages, the zinc accumulating in the soil should be extracted from the contaminated ecosystems to insure a growth balance between plant tolerance and plant productivity. To do so, several physical and chemical methods are currently in use but they are mostly costly and cumbersome (Jabeen et al. 2009). Biological methods, on the other hand, are cost-effective and can be interesting alternatives to physio-chemical methods particularly for low-to-moderately contaminated soils. Phytoremediation is indeed one of the most sustainable and ecofriendly methods to reduce metals toxicity in agricultural environments.

Phytoremediation approaches consist of growing plant and/or microorganism species in soils contaminated with heavy or toxic metals so that plants can absorb the contaminants and accumulate them in their tissues (Ali et al. 2013). Fast-growing trees, such as Salix sp with its high genetic variability, are good candidates for such purposes (Punshon and Dickinson 1997). The genus Salix (a member of the Salicaceae family) contains more than 400 species and hundreds of hybrid trees and shrubs (Newsholme 1992). Most of these species are characterized by rapid growth and high biomass accumulation that make them potential candidates for heavy metals phytoremediation (Shanahan et al. 2007) (Mleczek et al. 2017) (Yang et al. 2018). The choice of Salix spp clones for zinc phytoremediation is based on some key criteria: bioaccumulation capacity, biomass growth performance, and genetic variations. Zinc bioaccumulation and zinc tolerance levels, however, vary between Salix spp clones (Greger and Landberg 1999) (Kubátová et al. 2018) (Yang et al. 2018). In tolerant species, plant can grow and thrive to some extent under stressful conditions, but the growth and biomass accumulation of non-tolerant Salix clones can be inhibited by zinc toxicity (Dickinson et al. 1992) (Pulford and Watson 2003). Growth inhibition is a limiting factor for 
phytoremediation processes (Dos Santos Utmazian et al. 2007) (Bernardini et al. 2016) (Wani et al. 2018).

To overcome such phytotoxicity-related issues, the research on plant tolerance has drawn more attention over the last years. Some of the strategies that have been developed to detoxify contaminated sites rely on plant species, by for example selecting and planting hyper accumulating species and/or transgenic plants with enhanced capacity for absorption, accumulation and tolerance of heavy metals (Jabeen et al. 2009). Other strategies are based on plant environment by for example exogenous applications of mineral chelators such as EDTA (Barocsi et al. 2003) or spermidine (Tang et al. 2019). Different studies report that plants growing nearby polluting sources, such as mining spills (Bradshaw 1952) or aerial deposition of heavy metals contribute to the acclimation of plants to toxic pollutants to some degree. For example, trees growing near factory chimneys have been acclimated to high concentrations of copper $(\mathrm{Cu})$, cadmium $(\mathrm{Cd})$ and zinc $(\mathrm{Zn})$ (Dickinson et al. 1992). Researchers have also succeeded in inducing tolerance in herbaceous species using low-dose of heavy metal pretreatments (Baker 1981). Punshon and Dickinson reported that progressive acclimation of Salix spp trees to some heavy metals can enhance the tolerance to other heavy metals (Punshon and Dickinson 1997).

Our objective here was to test cumulative effects of low concentrations of zinc in Salix sp clones at short and regular intervals with the goal to induce an acquired zinc tolerance and to maintain it as long as possible. We followed a straightforward and simple approach consisting of two phases: 1) an induction phase to trigger adequate physiological and molecular responses to zinc toxicity, and 2) an acquisition phase to maintain the acquired zinc tolerance that corresponds to the maximum tolerated zinc concentration reached during the induction phase. The maintenance concentration is then provided at more spaced intervals than in the induction phases in attempt to maintain zinc tolerance as long as it could be.

\section{Materials and methods}

\section{Plant material}

A collection of Salix Pedicellata clones from the National Institute of Forest Research INRF - Bainem (Algiers, Algeria) has been used. The geographical origin of the clones is an eastern Algerian region called Oued ElKebir El-Kala, characterized by a Mediterranean climate conditions with an average annual precipitation of about $900-2000 \mathrm{~mm} / \mathrm{year}$, and temperature ranges of about $12^{\circ} \mathrm{C}$ in winter and $26.1{ }^{\circ} \mathrm{C}$ in summer. The region is dominated by tall Alnus glutinosa trees and Salix spp. The shrubs of the collection were growing on a 
homogeneous plot and fertilized with NPK (nitrogen, phosphorous, and potassium) and irrigated regularly.

\section{Preliminary experiments for zinc phytotoxicity determination}

A dozen of randomly harvested clones were propagated by cuttings on perlite in a greenhouse and grown at temperature of $25 \pm 2^{\circ} \mathrm{C}$ and $80 \%$ relative humidity. The obtained seedlings are then transferred into a hydroponic culture system in $250 \mathrm{ml}$ containers filled with perlite (an inert medium to support roots). A sample of 34 plants per clone and per concentration was then treated with zinc sulfate $\left(\mathrm{ZnSO}_{4}\right)$ at the following concentrations: $1 \mathrm{mg} / \mathrm{L}, 3 \mathrm{mg} / \mathrm{L}$, $6 \mathrm{mg} / \mathrm{L}, 10 \mathrm{mg} / \mathrm{L}, 15 \mathrm{mg} / \mathrm{L}, 20 \mathrm{mg} / \mathrm{L}$ and $30 \mathrm{mg} / \mathrm{L}$. Based on the percentage of growing plants, the concentrations of $\mathrm{ZnSO}_{4}$ at $6 \mathrm{mg} / \mathrm{L}$ and $20 \mathrm{mg} / \mathrm{L}$ have been shown to be inhibiting thresholds that inhibit the growth of about $50 \%\left(\mathrm{DI}_{50}\right)$ and $100 \%\left(\mathrm{DI}_{100}\right)$ of the growing plants, respectively.

\section{Tolerance induction in Salix pedicellata clones}

Two Salix clones (SP-K12 and SP-K20) were retained for the treatments with zinc (ZnSO4), though similar responses have been observed in other clones. Twigs of about $8 \mathrm{~mm}$ in diameter were collected from healthy two years old trees in the spring of 2017 , and then cut into cuttings of $20 \mathrm{~cm}$ in length. The cuttings of each clone were randomized and planted in perlite at a depth of $5 \mathrm{~cm}$ and transferred into in a glass greenhouse with a nebulization system at a temperature of $25 \pm 2^{\circ} \mathrm{C}$ and a relative humidity of $80 \%$ for 25 days. When the roots appeared, the shoots have been cut and the roots reduced to about $1 \mathrm{~cm}$ in length. Each stem was containing six dormant buds in average. The obtained plants are then placed in $250 \mathrm{ml}$ containers filled with perlite to be installed in a hydroponic culture system for the treatments of zinc.

\section{Hydroponic culture system}

A hydroponic culture system composed of $\varnothing 80$ PVC tubes, pots, pump, filter and a nutrient solution reservoir (10 L capacity) was used (Figure 1). The nutrient solution (Hoagland's solution) (Hoagland and Arnon 1950) is composed of the following elements (dissolved in distilled water): $\mathrm{KNO}_{3}: 151.6 \mathrm{mg} / \mathrm{L}, \mathrm{Ca}\left(\mathrm{NO}_{3}\right) 2 \cdot{ }_{4} \mathrm{H}_{2} \mathrm{O}, 236.1 \mathrm{mg} / \mathrm{L}, \mathrm{NH}_{4} \mathrm{H}_{2} \mathrm{PO}_{4}: 57.5 \mathrm{mg} / \mathrm{L}$, $\mathrm{MgSO}_{4} \cdot 7 \mathrm{H}_{2} \mathrm{O}: 61.6 \mathrm{mg} / \mathrm{L}, \mathrm{KCl}: 0.93 \mathrm{mg} / \mathrm{L}, \mathrm{MnSO}_{4} \cdot \mathrm{H}_{2} \mathrm{O}: 0.08 \mathrm{mg} / \mathrm{L}, \mathrm{H}_{3} \mathrm{BO}_{3}: 0.39 \mathrm{mg} / \mathrm{L}$, $\mathrm{ZnSO}_{4} \cdot 5 \mathrm{H}_{2} \mathrm{O}: 0.08: \mathrm{mg} / \mathrm{L}, \mathrm{CuSO}_{4} \cdot 5 \mathrm{H}_{2} \mathrm{O}: 0.38 \mathrm{mg} / \mathrm{L}, \mathrm{H}_{2} \mathrm{MoO}_{4}: 0.08 \mathrm{mg} / \mathrm{L}, \mathrm{Fe}-\mathrm{Na}$ EDTA: $1.73 \mathrm{mg} / \mathrm{L}$. The nutrient solution circulates in the tubes $24 \mathrm{~h} / 24 \mathrm{~h}$ to feed the growing plants by capillarity. To avoid root hypoxia, the nutrient solution is maintained under continuous 
ventilation and oxygenation by aquaculture aerators equipped with a pump and filter. The plants undergoing the treatments with zinc are called "induced plants"; and non-treated plants are controls. Four treatment systems have been used (Figure $1 \mathrm{~A}$ ): two for control plants and two for plants induced at a rate of one clone per system. Each system contains 34 plants in four combinations: control SP-K12, induced SP-K12, control SP-K20 and induced SP-K20. The experiments were carried out in a culture chamber at a temperature of $25 \pm 2^{\circ} \mathrm{C}$.

\section{Approach to induce zinc tolerance by accumulating low concentrations of $\mathrm{ZnSO}_{4}$}

A stock solution of zinc was prepared at a concentration of $1 \mathrm{mg} / \mathrm{mL} \mathrm{ZnSO}_{4}$ in distilled water. The volumes of the treatments solution are then used to prepare the desired concentrations of $\mathrm{ZnSO}_{4}$ (Table 1) in culture containers adjusted up to 10 liters with Hoagland solution. The same volumes $(10 \mathrm{~L})$ of distilled water with Hoagland solution were used for the control without zinc supply. The $\mathrm{pH}$ of culture media was adjusted to 5.8 (with $\mathrm{HCl} 1 \mathrm{M}$ and $\mathrm{NaOH} 1 \mathrm{M}$ ). The nutrient solutions containing the cumulative concentrations of $\mathrm{ZnSO}_{4}$ were renewed every three days (Table 1). At the beginning of the experiment (day 0), $1 \mathrm{mg} / \mathrm{L} \mathrm{ZnSO}_{4}$ was added to 10 liters of Hoagland solution $(10 \mathrm{mg} \mathrm{ZnSO} 4$ in $10 \mathrm{~L}$ culture solution). Then, on the $3^{\text {rd }}$ day of the experiment, the hydroponic system is discarded and replaced with new fresh solution containing $2.10 \mathrm{mg} / \mathrm{L} \mathrm{ZnSO}_{4}$, and so on. That is, the initial zinc concentration is increased each time by an additional $1.10 \mathrm{mg} / \mathrm{L} \mathrm{ZnSO}_{4}$, until reaching a cumulative concentration of $20 \mathrm{mg} / \mathrm{L} \mathrm{ZnSO}_{4}$, which marks the end of phase 1 and corresponds to the $\mathrm{DI}_{100}$.

During the second phase, the concentration of $20 \mathrm{mg} / \mathrm{L} \mathrm{ZnSO}_{4}$, called the maintenance concentration (Table 1), is added once every 6 days. This concentration is provided at the double interval of the first phase to maintain the acquired tolerance. The sulfate $\left(\mathrm{SO}_{4}{ }^{2-}\right)$ provided by $\mathrm{ZnSO}_{4}$ was not taken into account because it is not part of heavy metals.

\section{Evaluation of induced tolerance with tolerance index}

The tolerance index can be calculated based on the biomass (Dos Santos Utmazian et al. 2007) (Yang et al. 2018) or, the average root's length (Punshon and Dickinson 1999) (Hakmaoui et al. 2007). However, in our case it is the average shoot's length that was used to calculate the tolerance index for two reasons: 1) shoot tolerance index is practical and nondestructive measure for plant material; 2) shoot tolerance index is comparable to root tolerance index or biomass weight index while being easier to perform. The zinc tolerance index is comparable between the shoot, root and overall biomass of Salix purpurea because 
zinc phytotoxicity results in similar inhibition patterns on the length of roots and shoots and the total fresh weight (Hakmaoui et al. 2007).

For each treatment, we measured the average shoot length using a caliper every three days of ten randomly selected plants. To follow up the evolution of induced tolerance, the measurements were performed on the same plants for 60 days of experimentation. Each measurement was carried out on three most developed shoots per plant. Then, the tolerance index has been calculated using the following formula:.

$$
\mathrm{TI}=(\mathrm{LMPi} / \mathrm{LMPc}) * 100
$$

Where TI is the tolerance index, LMPi is the means shoot length of the induced plants and LMPc is the means shoot length of control plants.

When TI is smaller than 100, the growth of induced plants is inhibited compared to the control. If $\mathrm{TI}=100$, the induced plants and controls have the same growth rates/lengths. And, when TI is bigger than 100, the induced plants show greater growth rates than the control plants.

\section{Evaluation of induced tolerance with biomass growth and zinc bioaccumulation}

The biomass of shoots and roots was determined by using a precision balance after drying fresh samples in an oven for 48 hours at $60^{\circ} \mathrm{C}$ then in a desiccator. The total dry biomass is the sum of biomass of aerial and root parts. To assess the zinc content, the dried shoots and roots were grinded, mineralized and digested: $500 \mathrm{mg}$ of dry powder were dissolved in $5 \mathrm{ml}$ of concentrated $\mathrm{HNO} 3$ for $1 \mathrm{~h}$ at $25 \mathrm{C}^{\circ}$ in a water bath, then in $10 \mathrm{ml}$ of a triacid concentrated mixture $\left(\mathrm{HNO}_{3}-\mathrm{H}_{2} \mathrm{SO}_{4}-\mathrm{HCl}_{4}\right)$ : at a mixture ratio of $\left.10-1-4\right)$ and heated to $200^{\circ} \mathrm{C}$ under reflux. When the digestion solution turns into is clear, tge digestion was deemed complete and the solution was filtered to remove any solid undissolved debris. The zinc assay was carried out by using a UV/VIS spectrophotometer (JENWAY, Cole-Parmer Ldt, UK) according to the method described by (Kiran 2012). The chemicals used were bought from Sigma-Aldrich and/or Merck. Each experiment has been replicated three times.

\section{Statistical analysis}

ANOVA (analysis of the variance) and Newman-Keuls tests were applied to compare the means of different testing groups using Statgraphics $18^{\circledR}$ software. The differences were 
considered significant at $p=0.01$ to $0.05\left(^{*}\right)$, highly significant at $p=0.001$ to 0.01 (**) and very highly significant at $p \leq 0.001(* * *)$. The Newman-Keuls method is a test used following an Anova analysis to compare multiple samples means to identify and rank the means based on statistical strength (Begun and Gabriel 1981): the means followed by the same alphabetical letters are not statistically different at a $5 \%$ level.

\section{Results}

\section{Acquisition of zinc tolerance}

During the induction phase of zinc tolerance, the SP-K12 clone seems to quickly acquire a certain ability of tolerance to zinc concentrations, up to $6.3 \mathrm{mg} / \mathrm{L} \mathrm{ZnSO}_{4}\left(\mathrm{DI}_{50}\right)$ at the $12^{\text {th }}$ day of treatment. The tolerance has been maintained up to $14.4 \mathrm{mg} \mathrm{ZnSO}_{4}$ administered on the $24^{\text {th }}$ day. Beyond this concentration, the clone becomes sensitive and its tolerance index decreases below the tolerance threshold (Figure 2).

Compared to the clone SP-K12, the tolerance index of the clone SP-K20 increases gradually during the induction phase to reach its maximum at the concentration of $14.4 \mathrm{mg} \mathrm{ZnSO}_{4}$ administered at the $24^{\text {th }}$ day of treatment. Beyond this, it decreases slightly and stabilizes during the phase of maintaining zinc tolerance above the tolerance threshold (Figure 2).

The $\mathrm{ZnSO}_{4}$ treatment has a highly significant effect on the biomass of the aerial parts and very highly significant on the root part (Table 2). The Newman-Keuls test distinguishes 3 homogeneous groups for the aerial part $(\mathrm{a}, \mathrm{b}, \mathrm{c})$ and for the root part $(\mathrm{A}, \mathrm{B}, \mathrm{C})$. The means followed by the same alphabetical letter are not statistically different at the $5 \%$ level according to Newman-Keuls test (Figure 3). At 60 days, the overall biomass (aerial and root parts) of the control plants of the clone SP-K12 was higher than that of the control of the clone SP-K20 (Figure 3). That is, the SP-K12 clone exhibits a more significant biomass growth rate than that of the SP-K20 clone. However, the trend is reversed in the induced plants. The overall biomass of the plants induced from the SP-K20 clone increases significantly compared to that of the SP-K12 clone's induced plants (Figure 3).Based on these results, the clone SP-K20 was selected to further to assess the acquired zinc tolerance over time.

\section{Evaluation of the acquired zinc tolerance in the clone SP-K20}

To evaluate the level of acquisition of zinc tolerance in the clone SP-K20, induced and noninduced (control) plants were treated with $20 \mathrm{mg} / \mathrm{L} \mathrm{ZnSO}_{4}$ at the $60^{\text {th }}$ day of the experiment. Six days after this treatment, the growth of biomass and the bioaccumulating zinc content 
have been observed and measured. We found that a concentration of $20 \mathrm{mg} / \mathrm{L} \mathrm{ZnSO}_{4} / \mathrm{l}$ has a significant effect on the overall biomass of the SP-K20 clone (Table 3). The comparisons of means by the Newman-Keuls test show that two homogeneous groups (a, b) were distinguished (Figure $4 \mathrm{~A}$ ). The growth rates of SP-K20 control plants were significantly inhibited compared to zinc induced-tolerance plants (Figure 4A), suggesting that the induced plants tolerate zinc accumulation better than the control at $\mathrm{DI}_{100}$ of $\mathrm{ZnSO}_{4}$. A chlorosis was also observed for SP-K20 control at $66^{\text {th }}$ day.

The effect of $20 \mathrm{mg} / \mathrm{L} \mathrm{ZnSO}_{4}$ was highly significant on the accumulation of zinc in plant tissues (Table 3). Three homogeneous groups (a, b, c) were distinguished based on the Newman-Keuls test analysis (Figure 4B). The bioaccumulating zinc content in zinc inducedtolerant plant populations is significantly higher than that in the control (Figure 4B). This confirms the initial hypothesis that the induced SP-K20 clone's plants accumulate high concentrations of zinc and continue to grow.

On another hand, a sample of SP-K20 zinc induced tolerant and non-induced tolerant populations were exposed to a lethal zinc concentration. For this, bare-rooted plants were immersed directly in a solution of $\mathrm{ZnSO}_{4}\left(500 \times \mathrm{DI}_{100}\right)$. Morphological plant responses were photographed and presented in Figure 5. The main reactions observed in the control plants include immediate wilt (after merely 12 hours (Figure 5a) and the appearance of chlorosis (Figure 5b) followed by $100 \%$ plant mortality after 48 hours of treatment.

For the induced plants, we observe a rigidity of the leaves (Figure 5a) and a blackening of the central rib and secondary veins (Figure 5c). The induced plants continue their apical growth after 48 hours of exposure (Figure 5c). These plants eventually die (100\%) after 96 hours of exposure.

\section{Discussion}

\section{Acquisition of zinc tolerance of SP-K12 and SP-K20 clones}

The present approach of induction of zinc tolerance comprises two phases; a tolerance induction phase and a tolerance maintenance phase (Table 1). Previously, it has been reported plant tolerance to heavy metals can be induced (within a period called an induction phase) in species harboring genetic variability with sensitive and resistant genotypes (Punshon and Dickinson 1997). Our results here on Salix pedicellata treated with zinc sulfate are consistent with this claim, despite some response variations between two Salix pedicillata clones, SPK12 and SP-K20, which nonetheless show an enhanced zinc tolerance. However, it is worth noting to distinguish two periods in acquiring zinc tolerance for SP-K12 and SP-K20 clones. 
The first ranges from 0 days to the $9^{\text {th }}$ day of the experiment where the cumulative concentrations of zinc are below the $\mathrm{DI}_{50}\left(6 \mathrm{mg} / \mathrm{L} \mathrm{ZnSO}_{4}\right)$. The second period extends beyond the $9^{\text {th }}$ day of the experiment where the cumulative concentrations of zinc are phytotoxic (> DI $\mathrm{I}_{50}$ ). When zinc concentrations do not reach phytotoxicity (first period), zinc plays an important role in the regulation of nitrogen metabolism, cell multiplication, photosynthesis and auxin synthesis in plants (Shier 1994) (Broadley et al. 2007). Thus, the increase of the tolerance index during the first nine days, which reflect a greater growth of induced plants than the control, could be explained by a fertilizing effect of $\mathrm{Zn}^{2+}$ and $\mathrm{SO}_{4}{ }^{2-}$ ions provided by the zinc sulfate $\left(\mathrm{ZnSO}_{4}\right)$.

During the second period ( $>9$ days), the tolerance is observed relatively to the phytotoxic concentrations of $\mathrm{ZnSO}_{4}$. Kopponen et al. (Kopponen et al. 2001) observed different potentials for copper and zinc tolerance in clones of the same population of Betula pendula and B. pubescens. We observed similar patterns in our study on Salix clones. Although the two clones SP-K12 and SP-K20 belong to S. pedicillata, they presented some differences in acquiring and maintaining zinc tolerance. The potential for acquiring metal tolerance depends on the type of ion, its concentration and the physiology of the plant (Thapa et al. 2012). So, there seems to be a physiological difference between SP-K12 and SP-K20. While the SP-K12 starts to be sensitive starting from $6.3 \mathrm{mg} \mathrm{ZnSO}_{4} / 1$ then it loses its tolerance completely beyond $14.4 \mathrm{mg} / \mathrm{L} \mathrm{ZnSO}_{4}$ (at the $24^{\text {th }}$ day), the clone SP-K20, on the other hand, shows a slight decrease in the tolerance between $14.4 \mathrm{mg}$ and $20 \mathrm{mg} / \mathrm{L} \mathrm{ZnSO} 4\left(\mathrm{DI}_{100}\right)$ before it stabilizes thereafter. This discrepancy might be due to the fact that metallic tolerance might be associated with major changes in the proteome composition (Kosová et al. 2011) (Thapa et al. 2012). At the proteomic level, the potential difference in toxicity tolerance in SP-K12 and SP-K20 could be explained by the difference in the level of expression of certain genes involved in zinc tolerance. In this regard, Konlechner et al., reported that the clone KH21 from Salix caprea was more tolerated to zinc than the clone KH20 and this tolerance seems to be linked to higher expression levels of the genes ScOASA1, ScCAD2, ScWAKL1 and ScRALFL1 whose protein products reduce the phytotoxicity of heavy metals (Konlechner et al. 2013). Phytotoxic concentrations of zinc inhibit many metabolic functions that delay plant growth and development (Nagajyoti et al. 2010) and cause chlorosis in leaves (Ebbs and Kochian 1997). Despite a slowdown in the growth rate of induced SP-K12 plants in our study, these plants did not show chlorosis symptoms, and this appears to be in discordance with previous findings by (Punshon and Dickinson 1997). In fact, these authors observed the appearance of chlorosis at the $57^{\text {th }}$ day of their experiment on Salix spp plants treated with 
gradual concentrations of $\mathrm{ZnSO}_{4}$ spanning through $2.5 \mathrm{mg} / \mathrm{L}$ (0 days), $5.0 \mathrm{mg} / \mathrm{L}$ ( $29^{\text {th }}$ day) and $7.5 \mathrm{mg} / \mathrm{L}$ ( $43^{\text {rd }}$ day). It should be noted, however, that the second concentration provided was twice that of the first one, and the contribution intervals were irregular. The onset of chlorosis prompted Punchon and Dickson (1997) (Punshon and Dickinson 1997) to discontinue zinc treatments and to deliver only Hoagland's solution for 28 days. But when the treatment was resumed on the $86^{\text {th }}$ day, the $\mathrm{ZnSO}_{4}$ concentration was $11.5 \mathrm{mg} / \mathrm{L}$, with an increase rate of $55.5 \%$ over the $7.5 \mathrm{mg} / \mathrm{L}$ concentration. The following increases of $\mathrm{ZnSO}_{4}$ until the end of the $128^{\text {th }}$ day experiment was irregular: $17.2 \mathrm{mg} / \mathrm{L}(42.8 \%)$ followed after 13 days by $25.8 \mathrm{mg} / \mathrm{L}$ (50\%) (Punshon and Dickinson 1997).

In our case, the effectiveness of the new two-phase induction approach would be to gradually stimulate the zinc tolerance mechanisms at low cumulative concentrations added at regular intervals. This procedure would be closer to natural behaviors where trees growing near factory chimneys have to acclimate to high concentrations of heavy metals upon aerial gradual deposition of $\mathrm{Cu}, \mathrm{Cd}$ and $\mathrm{Zn}$ (Dickinson et al. 1996). Therefore, the phytotoxicity severity of heavy metals may vary, depending on whether the exposure is acute or chronic. For Salix, chronic and slow exposure appears to be more effective in the acquisition of induced tolerance than acute and prompt exposures to high concentrations of heavy metals (Punshon and Dickinson 1997). This suggests that zinc tolerance of the clone SP-K12 can be improved by decreasing the concentrations of $\mathrm{ZnSO}_{4}$ being applied while lengthening the supply intervals at the same time to induce gradual and positive chronic cumulative effects.

A result obtained in this work shows a significant link between the growth biomass and the potential for acquiring zinc tolerance of clone. Indeed, SP-K12 grows faster but is less able to acquire zinc tolerance than SP-K20. There is thus an inverse relation between the speed of growth of biomass and the ability to acquire zinc tolerance. The confirmation of these results by future work would provide a first phenotypic indicator on the potential for acquiring tolerance.

\section{Evaluation of the acquired tolerance of SP-K20 clone}

Plant tolerance to heavy metals is the result of a complex combination of physiological, molecular and biochemical responses including avoidance, absorption and sequestration and detoxification of the toxic metal elements (Baker 1987) (Dickinson et al. 1992). In Salix spp cadmium-tolerant clones, it was reported that some clones were able to accumulate low levels of cadmium (Punshon and Dickinson 1997) while other clones have accumulated relatively high amounts of other metals such as zinc (Pulford and Watson 2003). That is, tolerance and 
absorption of heavy metals depend on the type of ion and on the plant clone or variety. The SP-K20 clone would develop different mechanisms of zinc absorption and detoxification, including for example, the synthesis of high levels of organic acids and the sequestration and vacuolar compartmentalization of the metal through the plasma membrane (Ernst et al. 1992) (Verkleij et al. 1998). Metallothioneins (proteins) and phytochelatines (peptides) are also involved in the detoxification of toxic heavy metals (Steffens 1990) (Zenk 1996). Such mechanisms might explain why SP-K20 zinc induced-tolerant plants have accumulated about 9 times more zinc than in the control $(5556.58 \mu \mathrm{g}$ Zn per plant versus $631.05 \mu \mathrm{g}$ in the control) upon only 6 days of treatment with $20 \mathrm{mg} / \mathrm{L}$ of $\mathrm{ZnSO}_{4}$. Moreover, the biomass of SPK20-induced plants has not been affected and the growing plants did not show any sign of phytotoxicity in contrary to control plants whose the growth has been hampered with seeable chlorosis symptoms.

In sum, the acclimation of Salix spp to heavy metals' phytotoxicity is more likely due to a cumulative (chronic) exposure (Punshon and Dickinson 1997). Our results confirm this observation, particularly when SP-K20 populations tolerated a high concentration of $\mathrm{ZnSO}_{4}$ $\left(500 \times \mathrm{DI}_{100}\right)$ twice longer than the control. The induced zinc tolerance in SP-K20 plants to such a shock zinc treatment confirms the effectiveness of gradual induction approach applied here. That is, regular and gradual accumulation of zinc, over short intervals, every three days for instance, would stimulate tolerance mechanisms and help maintaining them active over a longer time.

\section{Conclusion}

A new tolerance induction approach has been attempted here to increase plant resistance to zinc toxicity in Salix pedicellata. The approach consisted of two phases: an induction phase and a maintenance phase. The induction phase implies the application of small concentrations at regular and short intervals and the maintenance phase involves the application of higher concentrations over longer intervals. Gradual concentrations of zinc supplied at regular and short intervals are two important parameters in the efficacy of the approach. However, the outcome depends on the zinc concentrations being used, the length of the interval between each treatment, and the genotype of the plant and its sensitivity. The Salix SP-K12 clone seems to acquire zinc tolerance upon exposure to moderate to mid-high zinc concentrations but it becomes sensitive when zinc concentrations increase beyond the tolerance threshold. On the other hand, moderate to low concentrations result in a chronic acclimation to zinc up to $\mathrm{DI}_{100}$. The phase of tolerance maintenance is reversible when the zinc concentration and/or 
the intervals change drastically. Other heavy metals may induce similar effects to zinc but empirical work will be required to figure it out. As contaminated soils rarely contain a single pollutant, the relationship between growth rates, agonist or antagonists effects of combinatory metals and the ability to acquire tolerance and/or sensitivity will also need to be investigated for the identification of the best conditions and genotypes that fit well for a good phytoremediation approach in contaminated soils.

\section{Disclosure: None}

Funding: This work was supported by the National Institute of Forestry Research (INRF). BP 37, Chéraga- Alger. Algeria.

\section{References}

Ali, H., E. Khan and M. A. Sajad (2013). "Phytoremediation of heavy metals--concepts and applications." Chemosphere 91(7): 869-881.

Baker, A. (1987). "Metal tolerance." New phytologist 106: 93-111.

Baker, A. J. M. (1981). "Accumulators and excluders - strategies in the response of plants to heavy metals." Journal of Plant Nutrition 3 (1-4): 643-654.

Barocsi, A., Z. Csintalan, L. Kocsanyi, S. Dushenkov, J. M. Kuperberg, R. Kucharski and P. I. Richter (2003). "Optimizing phytoremediation of heavy metal-contaminated soil by exploiting plants' stress adaptation." Int J Phytoremediation 5(1): 13-23.

Begun, J. M. and K. R. Gabriel (1981). "Closure of the Newman-Keuls multiple comparisons procedure." Journal of the American Statistical Association 76 (374): 241-245.

Bernardini, A., E. Salvatori, S. Di Re, L. Fusaro, G. Nervo and F. Manes (2016). "Natural and commercial Salix clones differ in their ecophysiological response to $\mathrm{Zn}$ stress." Photosynthetica 54(1): 56-64.

Bradshaw, A. D. (1952). "Populations of Agrostis tenuis resistant to lead and zinc poisoning." Nature 169 (4313): 1098.

Broadley, M. R., P. J. White, J. P. Hammond, I. Zelko and A. Lux (2007). "Zinc in plants." New Phytol 173 (4): 677-702.

Chaney, R. (1993). Zinc phytotoxicity. Zinc in soils and plants, Springer: 135-150.

Dickinson, N. M., A. P. Turner, S. A. Watmough and N. W. Lepp (1992). "Acclimation of Trees to Pollution Stress: Cellular Metal Tolerance Traits." Annals of Botany 70(6): 569-572.

Dickinson, N. M., S. A. Watmough and A. P. Turner (1996). "Ecological impact of 100 years of metal processing at Prescot, northwest England." Environmental Reviews 4(1): 8-24. 
Dos Santos Utmazian, M. N., G. Wieshammer, R. Vega and W. W. Wenzel (2007). "Hydroponic screening for metal resistance and accumulation of cadmium and zinc in twenty clones of willows and poplars." Environmental Pollution 148 (1): 155-165.

Ebbs, S. D. and L. V. Kochian (1997). "Toxicity of zinc and copper to Brassica species: implications for phytoremediation." Journal of Environmental Quality 26(3): 776-781.

Ernst, W., J. Verkleij and H. Schat (1992). "Metal tolerance in plants." Acta botanica neerlandica 41(3): 229-248.

Fahad R, Zikria Z, Zulfiqar W, Muhammad R, Muhammad A, Mir Abdus Salam, Muhammad \& Waseem K (2019) Phytoaccumulation of $\mathrm{Zn}, \mathrm{Pb}$, and $\mathrm{Cd}$ in Conocarpus lancifolius irrigated with wastewater: does physiological response influence heavy metal uptake? International Journal of phytoremediation, "Forthcoming". DOI: 10.1080/15226514.2019.1658711

Greger, M. and T. Landberg (1999). "Use of Willow in Phytoextraction." International Journal of Phytoremediation 1(2): 115-123.

Hakmaoui, A., M. Ater, K. Boka and M. Baron (2007). "Copper and cadmium tolerance, uptake and effect on chloroplast ultrastructure. Studies on Salix purpurea and Phragmites australis." Zeitschrift für Naturforschung C 62(5-6): 417-426.

Hoagland, D. R. and D. I. Arnon (1950). "The water-culture method for growing plants without soil." Circular. California agricultural experiment station 347 (2nd edit).

Jabeen, R., A. Ahmad and M. Iqbal (2009). "Phytoremediation of heavy metals: physiological and molecular mechanisms." The Botanical Review 75(4): 339-364.

Kiran, K. (2012). "Spectrophotometric determination of zinc in water samples using 3hydroxybenzylaminobenzoic acid." Chemical Science Transactions 1: 669-673.

Konlechner, C., M. Türktaş, I. Langer, M. Vaculík, W. W. Wenzel, M. Puschenreiter and M.-T. Hauser (2013). "Expression of zinc and cadmium responsive genes in leaves of willow (Salix caprea L.) genotypes with different accumulation characteristics." Environmental pollution 178: 121-127.

Kopponen, P., M. Utriainen, K. Lukkari, S. Suntioinen, L. Kärenlampi and S. Kärenlampi (2001). "Clonal differences in copper and zinc tolerance of birch in metal-supplemented soils." Environmental Pollution 112 (1): 89-97.

Kosová, K., P. Vítámvás, I. T. Prášil and J. Renaut (2011). "Plant proteome changes under abiotic stress - contribution of proteomics studies to understanding plant stress response." Journal of proteomics 74(8): 1301-1322.

Kubátová, P., J. Száková, K. Břendová, S. Kroulíková-Vondráčková, F. Mercl and P. Tlustoš (2018). "Effects of summer and winter harvesting on element phytoextraction efficiency of Salix and Populus clones planted on contaminated soil." International Journal of Phytoremediation 20(5): 499-506.

Mleczek, M., P. Rutkowski, P. Goliński, Z. Kaczmarek, K. Szentner, B. Waliszewska, M. Stolarski and S. Szczukowski (2017). "Biological diversity of Salix taxa in $\mathrm{Cu}, \mathrm{Pb}$ and $\mathrm{Zn}$ phytoextraction from soil." International journal of phytoremediation 19(2): 121-132.

Nagajyoti, P. C., K. D. Lee and T. Sreekanth (2010). "Heavy metals, occurrence and toxicity for plants: a review." Environmental chemistry letters 8(3): 199-216.

Newsholme, C. (1992). "Willows: the genus Salix. Portland." Timber Pragg. 
Nriagu, J. O. and J. M. Pacyna (1988). "Quantitative assessment of worldwide contamination of air, water and soils by trace metals." Nature 333 (6169): 134-139.

Pulford, I. D. and C. Watson (2003). "Phytoremediation of heavy metal-contaminated land by treesa review." Environment International 29(4): 529-540.

Punshon, T. and N. Dickinson (1999). "Heavy metal resistance and accumulation characteristics in willows." international Journal of Phytoremediation 1(4): 361-385.

Punshon, T. and N. M. Dickinson (1997). "Acclimation of Salix to metal stress." New Phytologist 137 (2): 303-314.

Saha, P., Shinde, O., \& Sarkar, S. (2017). Phytoremediation of industrial mines wastewater using water hyacinth. International journal of phytoremediation, 19(1), 87-96.

Shanahan, J. O., J. E. Brummer, W. C. Leininger and M. W. Paschke (2007). "Manganese and zinc toxicity thresholds for mountain and Geyer willow." International journal of phytoremediation 9(5): 437-452.

Shier, W. T. (1994). "Metals as toxins in plants." Journal of Toxicology: Toxin Reviews 13(2): 205216.

Steffens, J. (1990). "The heavy metal-binding peptides of plants." Annual review of plant biology 41(1): 553-575.

Stevenson, A. C., J. Skinner, G. E. Hollis and M. Smart (1988). "The El Kala national park and environs, Algeria: an ecological evaluation." Environmental conservation 15(4): 335-348.

Tang, C., R. Zhang, X. Hu, J. Song, B. Li, D. Ou, X. Hu and Y. Zhao (2019). "Exogenous spermidine elevating cadmium tolerance in Salix matsudana involves cadmium detoxification and antioxidant defense." Int J Phytoremediation 21(4): 305-315.

Thapa, G., A. Sadhukhan, S. K. Panda and L. Sahoo (2012). "Molecular mechanistic model of plant heavy metal tolerance." Biometals 25(3): 489-505.

Verkleij, J. A., P. L. Koevoets, M. M. Blake-Kalff and A. N. Chardonnens (1998). "Evidence for an important role of the tonoplast in the mechanism of naturally selected zinc tolerance in Silene vulgaris." Journal of Plant Physiology 153 (1-2): 188-191.

Wani, W., K. Z. Masoodi, A. Zaid, S. H. Wani, F. Shah, V. S. Meena, S. A. Wani and K. A. Mosa (2018). "Engineering plants for heavy metal stress tolerance." Rendiconti Lincei. Scienze Fisiche e Naturali 29(3): 709-723.

Yadav, K. K., N. Gupta, A. Kumar, L. M. Reece, N. Singh, S. Rezania and S. A. Khan (2018). "Mechanistic understanding and holistic approach of phytoremediation: a review on application and future prospects." Ecological engineering 120: 274-298.

Yang, W., F. Zhao, Z. Ding, M. J. I. Shohag, Y. Wang, X. Zhang, Z. Zhu and X. Yang (2018). "Screening of 19 Salix clones in effective phytofiltration potentials of manganese, zinc and copper in pilot-scale wetlands." International journal of phytoremediation 20(13): 1275-1283.

Zenk, M. H. (1996). "Heavy metal detoxification in higher plants-a review." Gene 179 (1): 21-30. 
Table 1. Salix phytoremediation phases, length and concentrations of zinc sulfate $\left(\mathrm{ZnSO}_{4}\right)$ being used in each phase.

\begin{tabular}{|c|c|c|c|c|}
\hline \multirow[t]{3}{*}{ Phases } & \multirow[t]{3}{*}{$\begin{array}{l}\text { Time } \\
\text { (Days) }\end{array}$} & \multicolumn{3}{|c|}{$\begin{array}{c}\mathrm{ZnSO}_{4} \text { treatment } \\
\text { (mg per liter of HS: Hoagland's solution) }\end{array}$} \\
\hline & & \multicolumn{2}{|c|}{ Induction } & \multirow[t]{2}{*}{ Control } \\
\hline & & $\begin{array}{c}\text { Low } \\
\text { concentrations } \\
(\mathrm{mg} / \mathrm{L})\end{array}$ & $\begin{array}{c}\text { Cumulated } \\
\text { concentrations } \\
(\mathrm{mg} / \mathrm{L})\end{array}$ & \\
\hline & 0 & 1.0 & 1.0 & HS \\
\hline & 3 & 1.1 & 2.1 & HS \\
\hline & 6 & 1.2 & 3.3 & HS \\
\hline & 9 & 1.4 & 4.7 & HS \\
\hline & 12 & 1.6 & 6.3 & HS \\
\hline Phase of zinc & 15 & 1.8 & 8.1 & HS \\
\hline Tolerance & 18 & 2.0 & 10.1 & HS \\
\hline \multirow[t]{5}{*}{ Induction } & 21 & 2.1 & 12.2 & HS \\
\hline & 24 & 2.2 & 14.4 & HS \\
\hline & 27 & 2.4 & 16.8 & HS \\
\hline & 30 & 2.6 & 19.4 & HS \\
\hline & 33 & - & 20.0 & HS \\
\hline \multirow{4}{*}{$\begin{array}{l}\text { Phase of zinc } \\
\text { Tolerance } \\
\text { Maintenance }\end{array}$} & 39 & & 20.0 & HS \\
\hline & 45 & & 20.0 & HS \\
\hline & 51 & & 20.0 & HS \\
\hline & 57 & & 20.0 & HS \\
\hline
\end{tabular}


Table 2. ANOVA test to compare the outcome of $\mathrm{ZnSO}_{4}$ treatments and biomass accumulation between SP-K12 and SP-K20 Salix $p$. clones.

\begin{tabular}{lllllll}
\hline \multicolumn{1}{c}{ Source } & \multicolumn{1}{c}{$\begin{array}{c}\text { Sum of } \\
\text { squares }\end{array}$} & $\begin{array}{c}\text { Degree } \\
\text { of } \\
\text { freedom }\end{array}$ & $\begin{array}{c}\text { Mean } \\
\text { squares }\end{array}$ & $\begin{array}{c}\text { F- } \\
\text { value }\end{array}$ & Probability & Signification \\
\hline Aerial part & \multicolumn{7}{c}{} & & & & \\
\hline Treatments & 22,63 & 3 & 7,54 & 14,10 & 0,002 & $* *$ \\
Error & 4,28 & 8 & 0,53 & & & \\
Total (Corr.) & 26,91 & 11 & & & & $* * *$ \\
\hline Root part & & & & & & \\
\hline Treatments & 0,97 & 3 & 0,32 & 20,54 & 0,000 & \\
Error & 0,13 & 8 & 0,02 & & & \\
Total (Corr.) & 1,10 & 11 & & & & \\
\hline
\end{tabular}


Table 3. ANOVA test to compare the effect of $20 \mathrm{mg} / \mathrm{L} \mathrm{ZnSO}_{4}$ on zinc bioaccumulation and biomass in the SP-K20 clone after 60 days of the treatment.

\begin{tabular}{|c|c|c|c|c|c|c|}
\hline Source & Sum of squares & $\begin{array}{l}\text { Degree } \\
\text { of } \\
\text { freedom }\end{array}$ & $\begin{array}{c}\text { Mean } \\
\text { squares }\end{array}$ & F-value & Probability & Signification \\
\hline \multicolumn{7}{|l|}{ Biomasse } \\
\hline Treatments & 62,45 & 3 & 20,82 & 29,27 & 0,0001 & $* * *$ \\
\hline Error & 5,69 & 8 & 0,71 & & & \\
\hline Total & 68,14 & 11 & & & & \\
\hline \multicolumn{7}{|c|}{ Zinc bioacumulation } \\
\hline Treatments & 53437000 & 3 & 17812333,30 & 75,77 & 0,0000 & $* * *$ \\
\hline Error & 1880750 & 8 & 235093,75 & & & \\
\hline Total & 55317700 & 11 & & & & \\
\hline
\end{tabular}



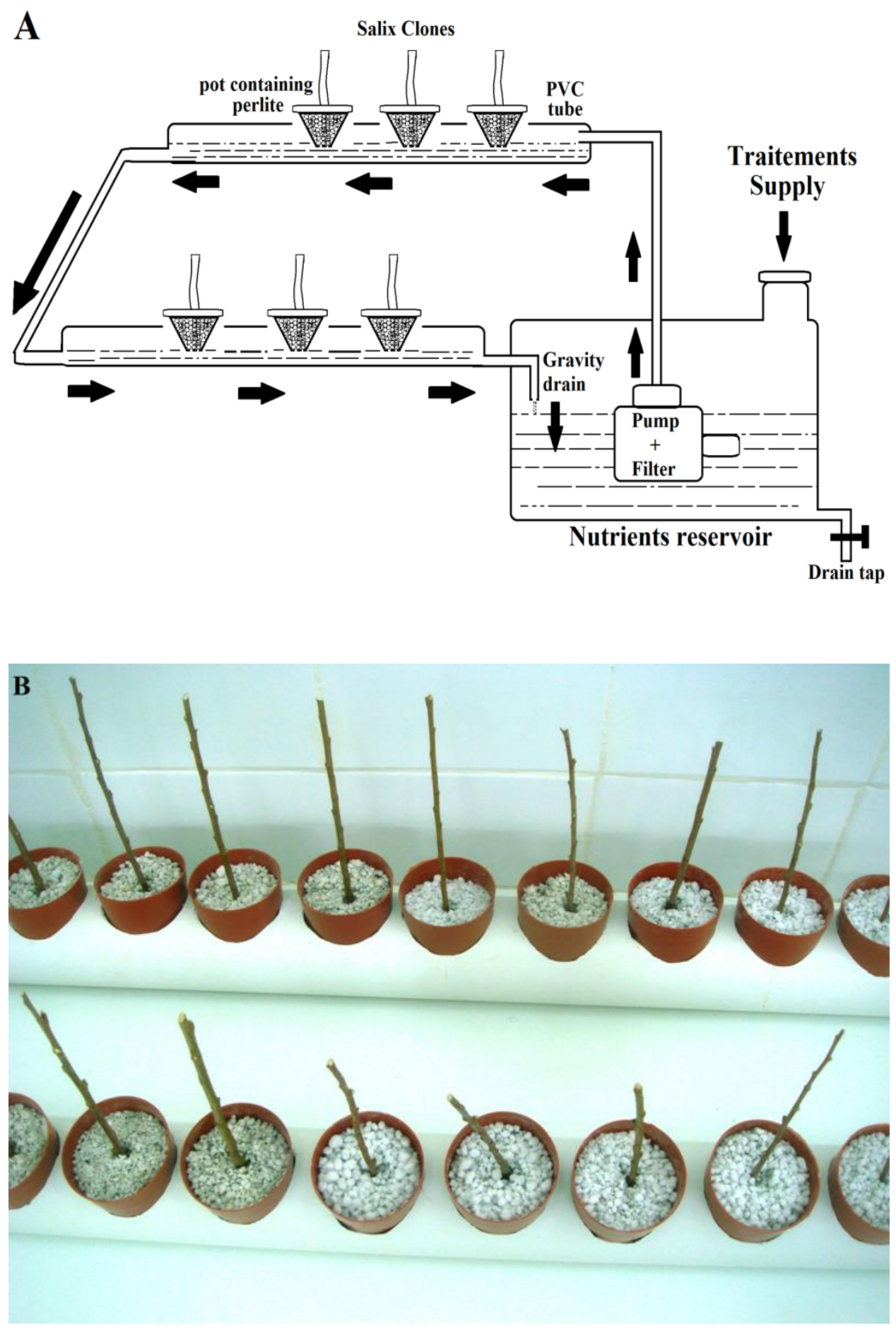

Figure 1. Salix hydroponic culture system. A): The different components of the culture system connected each to other (nutrient reservoir, PVC tubes, pots, pump, filter and drain tab). B): Salix cuttings placed in pots (red) filled with perlite (the white matter) and installed in PVC tubes (white) with fit diameters. 
-Tolerence Index of SP-K12 clone

$\Delta$ Phase of Tolerance Induction
— Tolerence Indice of SP-K 20 clone

$\Delta$ Phase of Tolerance Maintenance

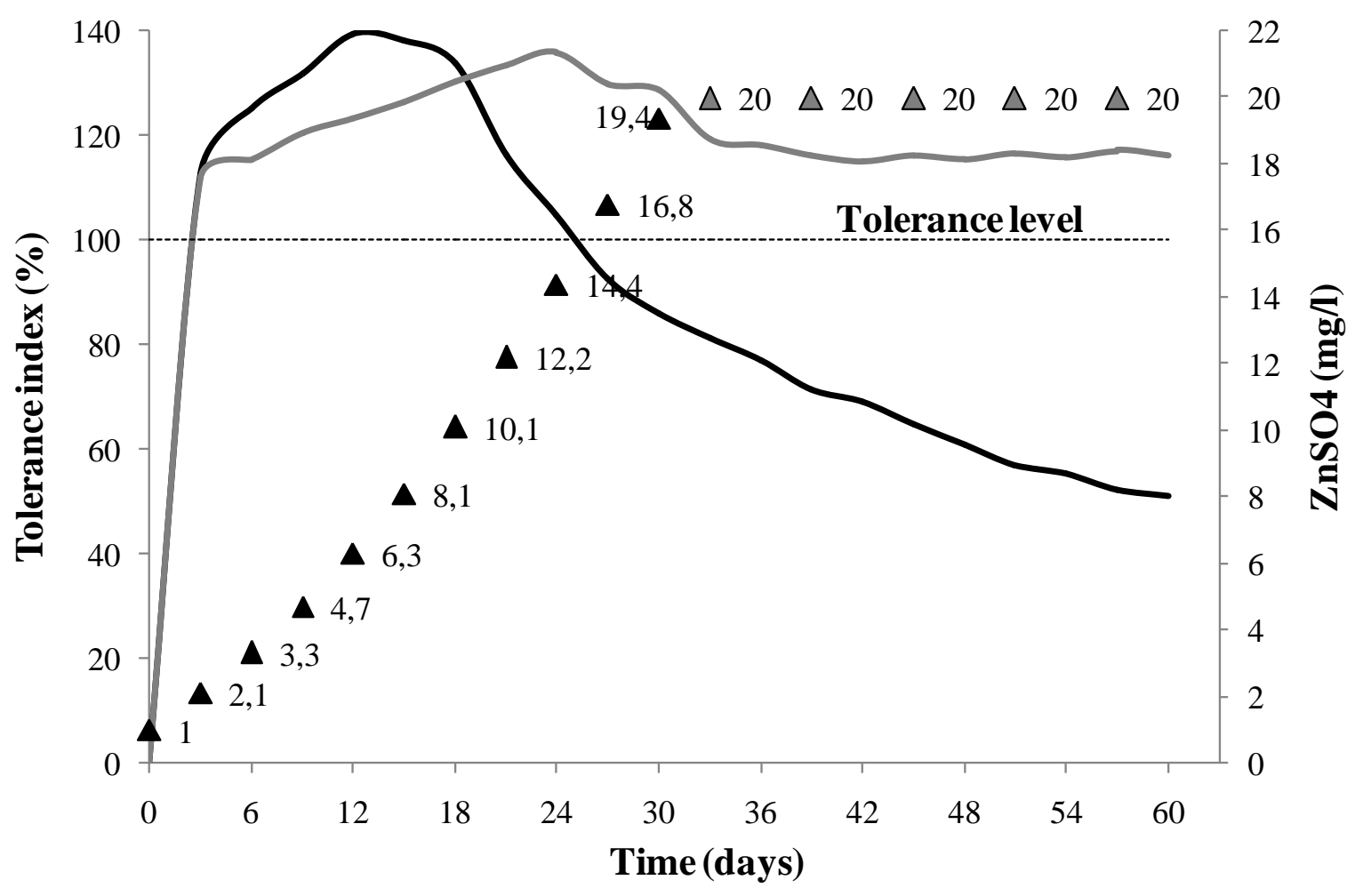

Figure 2. Evolution of the tolerance index (TI) in S. pedicellata SP-K12 and SP-K20 clones exposed to low cumulative concentrations of $\mathrm{ZnSO}_{4}$. 


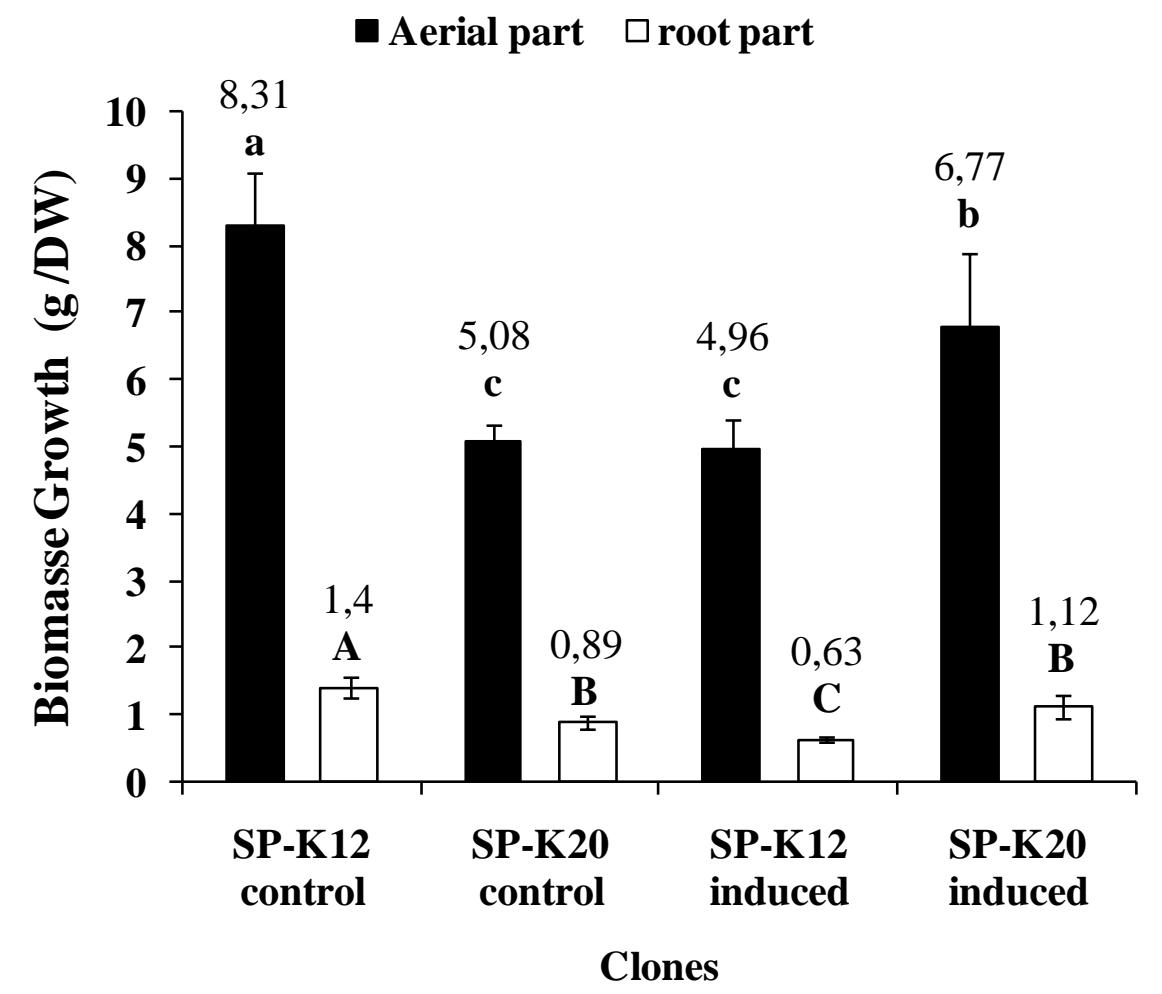

Figure 3. Biomass growth of S. pedicellata SP-K12 and SP-K20 clones exposed to low cumulative concentrations of $\mathrm{ZnSO}_{4}$ at the $60^{\text {th }}$ days of treatment (Means followed by the same alphabetical letter are not statistically different at the 5\% level according to NewmanKeuls method). 
A

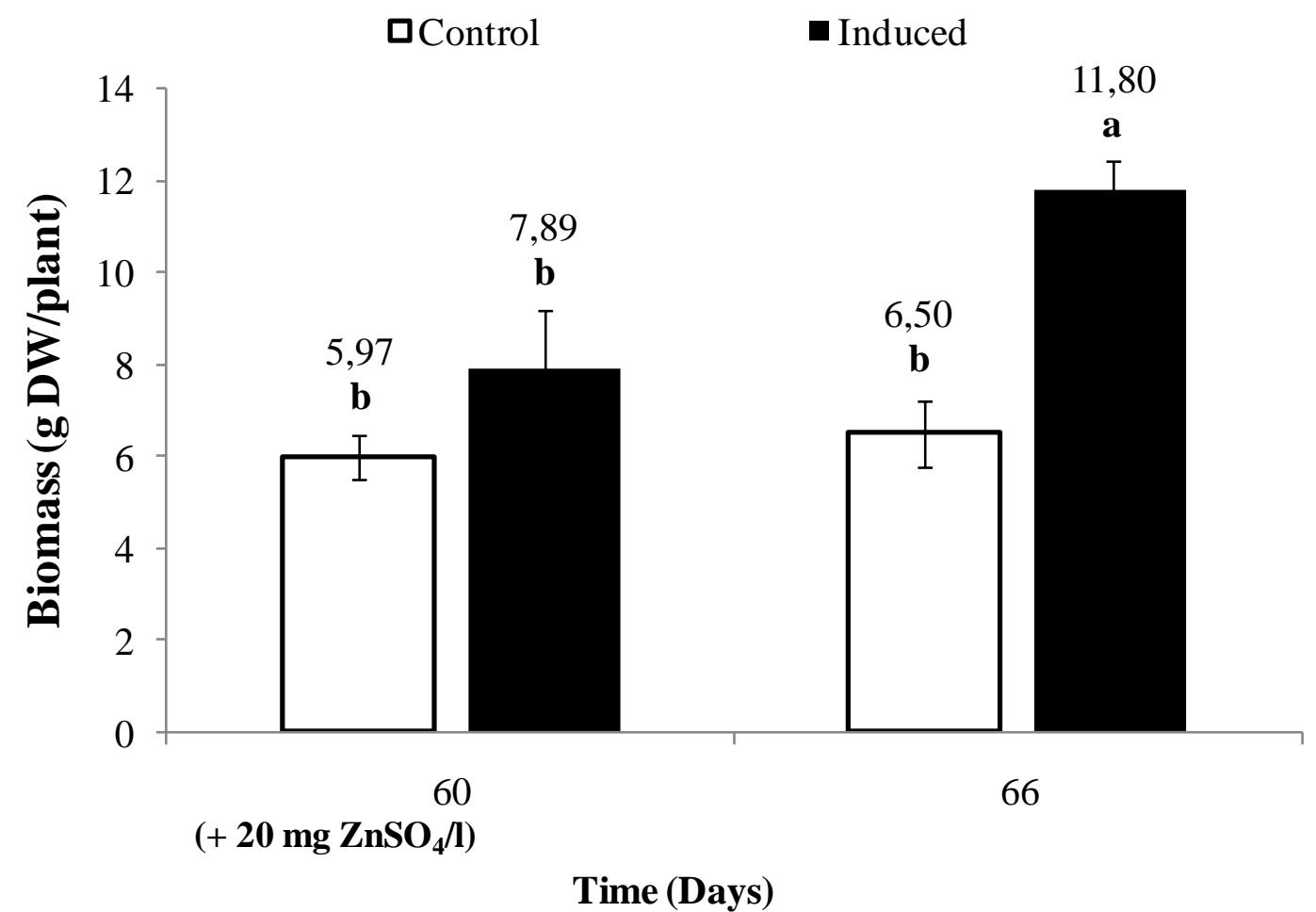

B

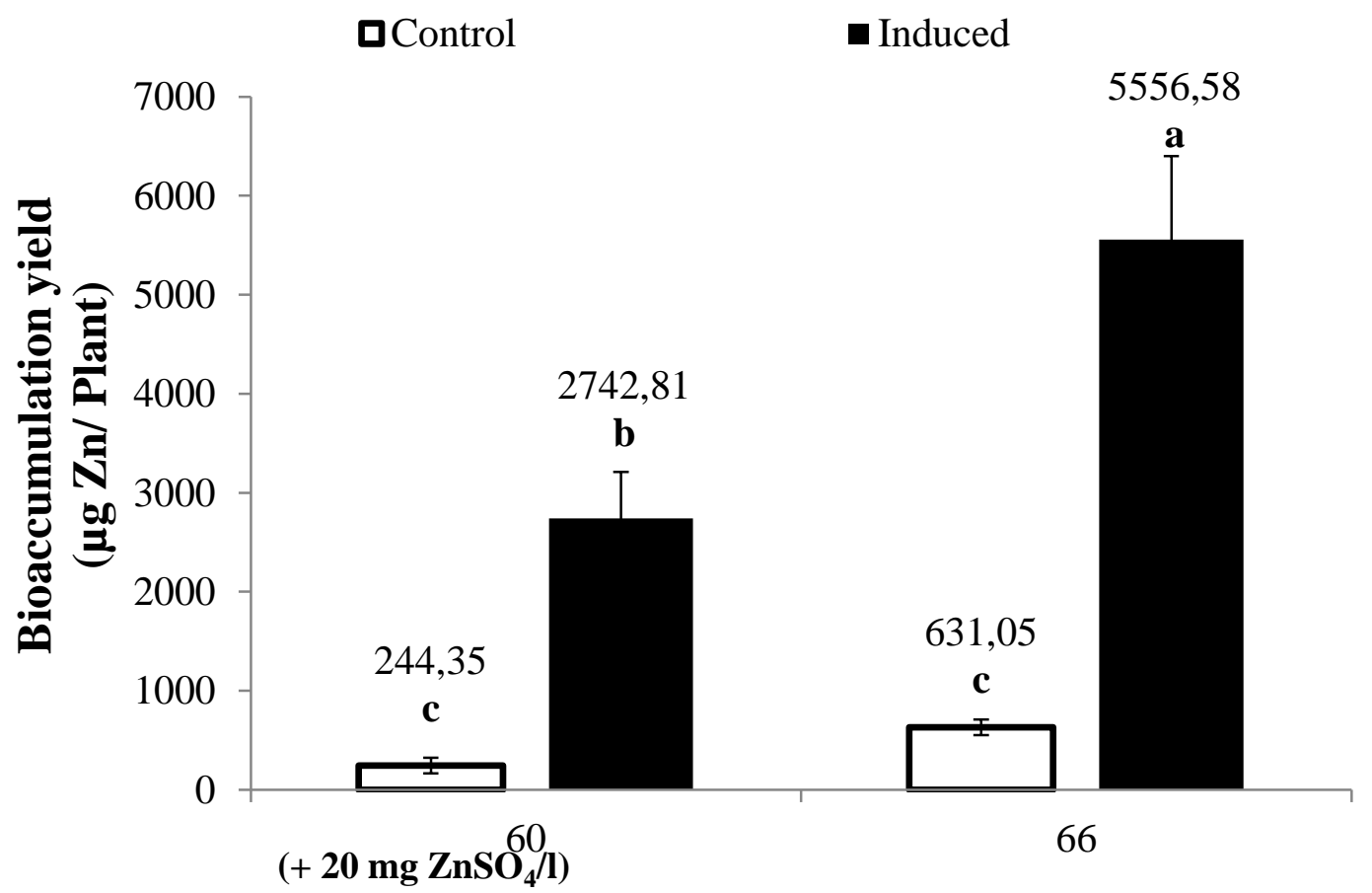

Time (Days)

Figure 4. Comparison of zinc tolerance between control and tolerance induced plants in Salix SP-K20 clone treated with $20 \mathrm{mg} / \mathrm{L} \mathrm{ZnSO}_{4}$ at the $60^{\text {th }}$ day of the experiment. (A): Growth and global biomass yield (including aerial and root parts). (B): Bioaccumulation yield of zinc in plant tissues (Means followed by the same alphabetical letter are not statistically different at the 5\% level according to Newman-Keuls method) 

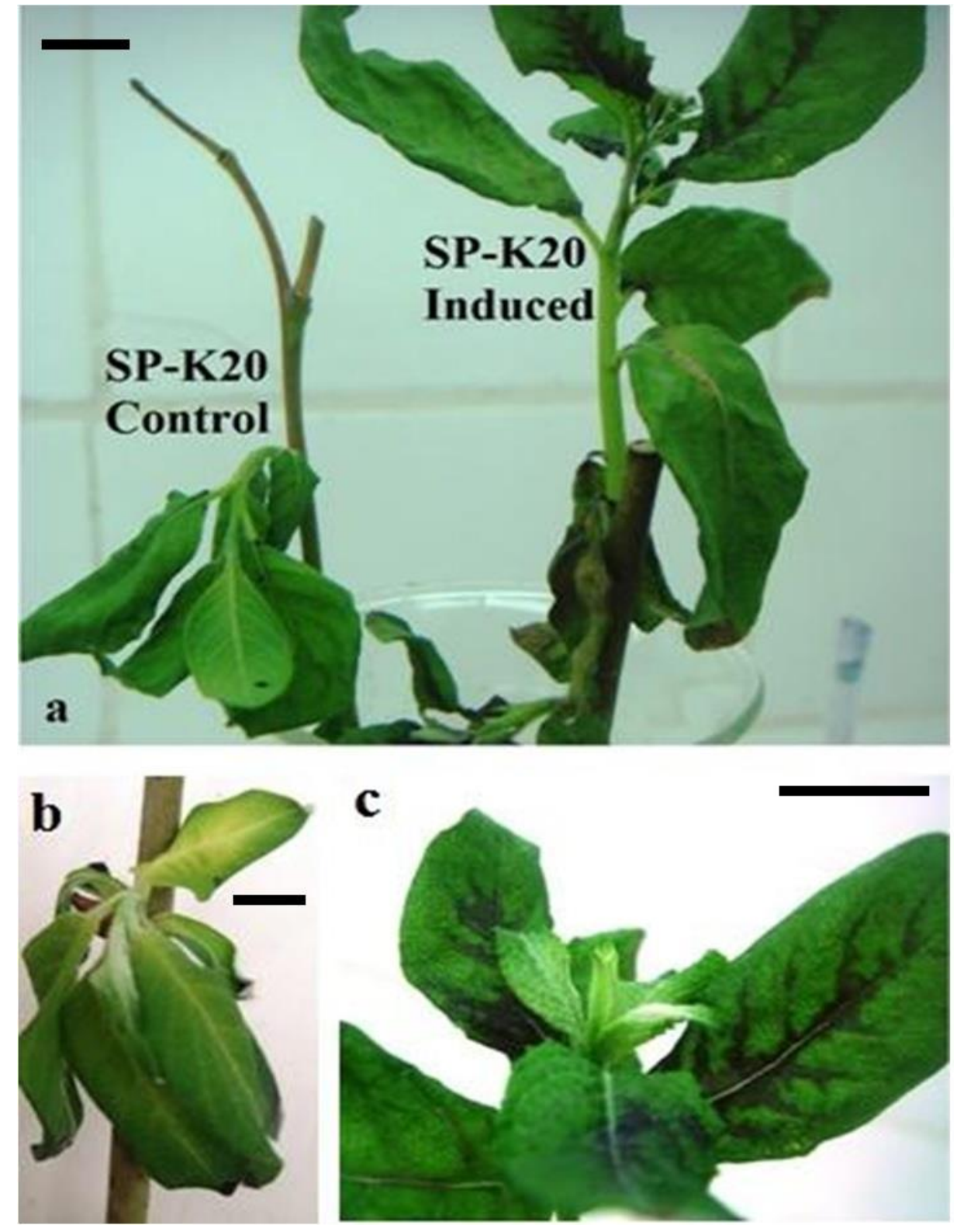

Figure 5. Morphological symptoms of the Salix SP-K20 clone's plants treated with zinc concentrations up to 500 -fold $\mathrm{DI}_{100}$. a: after 12 hours of exposure, the shoot wilt in the control (100\% mortality after 48 hours) and leaf stiffness in tolerance-induced plants. $\mathbf{b}$ : Chlorosis symptoms in the control after 24 hours of exposure. c: Blackening of central and secondary veins of plants induced after 12 hours of exposure. Apical growth in induced plants after 48 hours of exposure to zinc (100\% mortality after 96 hours of treatment). 